\title{
The Benefits of Exercise and Yoga for Breast Cancer Patients and Survivors
}

\author{
Kristalyn K Gallagher* \\ Department of Surgery, University of North Carolina, USA
}

Submission: November 25, 2017; Published: November 30, 2017

*Corresponding author: Kristalyn K Gallagher, Lineberger Comprehensive Cancer Center, Department of Surgery, University of North Carolina at Chapel Hill, Chapel Hill, NC, USA, Tel: 919-966-5221; Fax: 919966 -8806; Email: kristalyn_gallagher@med.unc.edu

\section{Editorial}

Maintaining an active lifestyle has a wide variety of health benefits. Regular exercise helps sustain a healthy weight, promotes cardiovascular health, reduces the risk of diabetes and stroke, improves blood flow to the brain, and releases endorphins improving mental stability-just to list a few. But can it also reduce cancer risk? Obesity has been shown to increase the risk of postmenopausal estrogen receptor (ER) positive breast cancer and associated mortality [1]. By promoting a healthier lifestyle, we may be able to reduce our individual risk.

So, what about women and men who have already been diagnosed with breast cancer? The benefits of exercise and yoga extend to breast cancer patients and survivors. Research shows that being overweight or obese is associated with a higher risk of secondary tumors, recurrence, and mortality. Physical activity is associated with improved outcomes in breast cancer survivors [2].

Exercise and yoga are commonly used by breast cancer patients as integrative therapies to reduce stress, increase flexibility, enhance muscle tone, and promote overall wellbeing. A diagnosis of breast cancer carries a psychological and emotional burden. Outside of psychological stressors, medical treatment has potential side effects that may be moderated by yoga and exercise. Complementing medical therapy with yoga and exercise has been shown to improve well-being in cancer survivors. Breast cancer is the most common cancer in women worldwide. In the United States, one in eight women are diagnosed over the course of their lifetime. Although risk increases with age, approximately $60 \%$ of patients who are diagnosed with breast cancer have no other identified risk factor. Obesity has been independently associated with an increased breast cancer risk $[3,4]$. Diet and exercise contribute to maintaining a healthy body mass index (BMI), which lower an individual's risk. Although breast cancer remains common, more women are surviving the condition. This improvement in overall survival is attributed to early diagnosis at presentation as well as more effective treatments and the utilization of targeted or personalized medical interventions. While increased survival is obviously a good thing, the large majority of breast cancer survivors do not make it through their journey unscathed. They will encounter psychological, physical, and emotional changes associated with their diagnosis and treatment. They may experience significant side effects that arise secondary to their cancer therapy. Conventional breast cancer treatment includes a combination of surgery, radiation, and systemic therapies-all of which have side effects. Integrative approaches incorporate diet and exercise regimens and mind-body practices that when used as complementary therapies may augment conventional treatments.

Surgery continues to be the mainstay for breast cancer treatment with curative intent. It is either performed primarily (at the time of diagnosis) or following neoadjuvant (preoperative) chemotherapy. Surgical techniques have significantly improved over the past 30 years. Surgical recommendations have focused on minimizing the extent of surgery without compromising survival. Recent advances have been made in breast conservation including thoughtful placement of surgical incisions to minimize scars, tissue rearrangement to minimize defects associated with tissue loss, and oncoplastic procedures to allow for resection of larger tumors while maintaining a more normal appearance of the breast. Women requiring mastectomy may be candidates to save the skin of the breast and possibly the nipple which significantly improves the cosmetic outcome following breast reconstruction. Despite these advances in surgical options, obesity still negatively impacts the surgical treatment. Obesity is associated with worse surgical outcomes, increased risk 
of infection, delayed wound healing, prolonged hospital stay and increased cost. It is also an independent risk factor for lymphedema, one of the most troublesome complications following breast cancer surgery.

Lymphedema is an abnormal accumulation of lymph (protein-rich interstitial fluid that gets trapped in the subcutaneous tissues) because of impaired lymphatic function. Lymphedema presents as arm swelling that ranges from mild discomfort with minimal swelling to severe swelling that limits function of the arm. Normally, lymph moves through lymphatic channels in the body as a passive process. During surgery, these channels may be damaged and normal drainage cannot occur. Risk factors for lymphedema include obesity (BMI >30 kg/m2), increased number of nodes resected during oncologic surgery, radiation therapy, high doses of paclitaxel, infection, and some specific genetic factors [5-7]. Muscle contraction during extremity movement helps move lymph fluid back toward the heart. Since this is dependent on a passive process, daily exercise and yoga can improve lymph flow by improved circulation and muscle tone.

A second common surgical complication after breast cancer surgery is decreased upper extremity range of motion. This is likely a result of scar formation and protective posturing in the immediate post-operative period. Following surgery, radiation is often recommended as part of the breast cancer treatment. Radiation causes changes in the targeted tissues leading to fibrosis and contracture or tightening of the tissues which can exacerbate the above symptoms. The effects of radiation are often delayed and not fully appreciated for months to years after the initial treatment. Yoga and stretching can help to soften these bands of scar tissue allowing for improved arm mobility and functionality. Yoga and exercise have been shown to improve flexibility, upper extremity strength, and range of motion. When performed regularly, they can help to improve upper extremity function. Systemic medical treatments for breast cancer include traditional cytotoxic chemotherapy as well as specifically targeted medications. Regular exercise may improve the delivery of chemotherapy to the targeted tissues and is associated with an increased likelihood of completion of all recommended therapy without requiring dose reduction [8]. Completion of the recommended treatment improves overall survival. In patients with hormone receptor (estrogen and/ or progesterone) positive breast cancer, systemic therapy also includes anti-estrogen medications. Adipose tissue expresses an enzyme called aromatase that converts circulating androgens into estrogens and can drive estrogen sensitive breast cancer growth. Exercise combined with strength training may help to reduce overall adipose tissue which in turn may reduce peripheral estrogen production.

Yoga and exercise have utility for managing side effects caused by breast cancer treatment. It also improves perceptual well-being. Obesity and sedentary lifestyle are associated with worse outcomes in breast cancer patients [1]. Yoga and regular exercise can improve flexibility and strength, promote weight loss, and reduce psychological stressors that directly impact health. When used as a complementary therapy, they are associated with improved outcomes for breast cancer patients and survivors [2].

\section{References}

1. Ruiz MP, Tarifa CM, Valle Goffin JJ, Friedman ER, Slingerland JM (2017) Obesity and adverse breast cancer risk and outcome: Mechanistic insights and strategies for intervention. CA Cancer J Clin 67(5): 378397.

2. Sheppard VB, Hicks J, Makambi K, Hurtado de Mendoza A, Wahnefried WD, et al. (2016) The feasibility and acceptability of a diet and exercise trial in overweight and obese black breast cancer survivors: The Stepping STONE study. Contemp Clin Trials 46: 106-113.

3. White AJ, Nichols HB, Bradshaw PT, Sandler DP (2015) Overall and central adiposity and breast cancer risk in the sister study. Cancer 121(20): 3700-3708.

4. Cecchini RS, Costantino JP, Cauley JA, Cronin WM, Wickerham DL, et al. (2012) Body mass index and the risk for developing invasive breast cancer among high-risk women in NSABP P-1 and STAR breast cancer prevention trials. Cancer Prev Res 5(4): 583-592.

5. Shih YCT, Xu Y, Cormier JN, Giordano S, Ridner SH, et al. (2009) Incidence, treatment costs, and complications of lymphedema after breast cancer among women of working age: a 2-year follow-up study. J Clin Oncol 27(12): 2007-2014

6. Petrek JA, Senie RT, Peters M, Rosen PP (2001) Lymphedema in a cohort of breast carcinoma survivors 20 years after diagnosis. Cancer 92(6): 1368-1377.

7. Gallagher K, Marulanda K, Gray S (2018) Surgical Intervention for Lymphedema. Surg Oncol Clin N Am 27(1): 195-215.

8. Costa M, Saldanha P (2017) Risk Reduction Strategies in Breast Cancer Prevention. Eur J Breast Health 13(3): 103-112. 


\section{Your next submission with Juniper Publishers} will reach you the below assets

- Quality Editorial service

- Swift Peer Review

- Reprints availability

- E-prints Service

- Manuscript Podcast for convenient understanding

- Global attainment for your research

- Manuscript accessibility in different formats ( Pdf, E-pub, Full Text, Audio)

- Unceasing customer service

Track the below URL for one-step submission https://juniperpublishers.com/online-submission.php 